\title{
JENIS-JENIS REPTILIA DI PPKA BODOGOL, TAMAN NASIONAL GUNUNG GEDE PANGRANGO
}

\author{
Debby Yuniar ${ }^{1}$, Hanum Isfaeni ${ }^{2}$, Paskal Sukandar ${ }^{2}$, dan Mohamad Isnin Noer ${ }^{1}$ \\ ${ }^{1}$ Prodi Biologi FMIPA Universitas Negeri Jakarta, Indonesia. ${ }^{2}$ Prodi Pendidikan Biologi FMIPA Universitas \\ Negeri Jakarta, Indonesia. \\ Email: db_yunihar@yahoo.co.id
}

\begin{abstract}
Studies about reptiles in of part of Java have been poorly known. Meanwhile, most of studies about diversity of reptiles which have been published were incorporated with amphibians, and nearly all just concern in unraveling the diversity of amphibians. In Bodogol, Gede-Pangrango National Park, survey about reptiles diversity have been done frequently, but just little research that have been published and most of all are short term research study. Hence, a research that concern in studying diversity of reptiles become valuable to carry out. Here, we studied the diversity of reptiles in Bodogol during November 2011 to March 2012. Reptiles' species were collected by searching in available trail, but Tangkil, Cipanyairan I, and Cipanyairan II. Total of twenty three species of reptiles were found, encompassing six families (Colubridae, Elapidae, Viperidae, Scincidae, Agamidae, and Gekkonidae). Based on this result, we assume that Bodogol is good habitat for reptiles because it serves high diversity of reptiles.
\end{abstract}

Key words : bodogol, diversity, reptiles, java

\section{PENDAHULUAN}

Pusat Pendidikan Konservasi Alam Bodogol (PPKAB)merupakan wilayah konservasi yang terletak di kaki gunung bagian selatan gunung gede pangrango. wilayah ini memiliki luas lebih dari 300 ha dan ketinggiannya berkisar antara 700-800 meter di atas permukaan laut. PPKAB didirikan pada tahun 1998, melalui konsorsium yang diprakarsai oleh Conservation International Indonesia, Balai Taman Nasional Gunung Gede Pangrango dan Yayasan Alam Mitra Indonesia. Kawasan ini merupakan salah satu zona pemanfaatan kawasan Taman Nasional Gunung Gede Pangrango (TNGGP) yang diupayakan dapat berperan serta dalam konservasi keanekaragaman hayati dan memperkenalkan kekayaan alam hutan hujan tropis kepada masyarakat umum dan masyarakat sekitar kawasan TNGGP (Ario, et al., 2011). Meskipun wilayah ini tidak terlalu luas, namun memiliki beberapa tipe habitat dan kondisi fisik yang mendukung sebagai habitat berbagai jenis flora. Faktor-faktor tersebut menjadi pendukung terhadap tingginya keanekaragaman fauna di Bodogol, termasuk reptilia.

Studi tentang reptilia di Jawa dan sekitarnya merupakan hal yang sangat menarik. Hingga saat ini, publikasi spesifik tentang reptilia di Jawa atau di beberapa wilayah di Jawa masih sangat jarang ditemukan. Hingga saat ini, studi tentang jenis-jenis reptilia di Jawa masih mengacu kepada de Rooij (1917), dan sebagian kecil publikasi jurnal dari LIPI (Mumpuni, 2001; Kurniati, 2004; Riyanto, 2011). Selain itu, sebagian besar studi reptilia selalu digabungkan dengan amfibi dan hampir keseluruhan hasil penelitian tersebut lebih mendeskripsikan tentang keanekaragaman 
amfibi.

Di bodogol, penelitian tentang reptilia sudah banyak dilakukan, namun hanya sedikit yang dipublikasikan. Selain itu, kegiatan-kegiatan penelitian tersebut merupakan penelitian singkat dan tidak mengeksploitasi jenis-jenis reptilia secara mendalam. Satu-satunya publikasi tentang reptilia hanya diperoleh dari Apririasari (2002) dan itupun hanya terfokus pada ular. Sangat sedikitnya informasi tersebut mengakibatkan pentingnya melakukan suatu penelitian yang terkonsentrasi terhadap keanekaragaman reptilia di Bodogol. Penelitian ini diharapkan dapat menjadi sumber acuan tentang penelitian reptilia di jawa dan juga dapat memberikan informasi terbaru mengenai jenis-jenis reptilia yang ada di kawasan tersebut.

\section{METODE PENELITIAN}

\section{LOKASI PENELITIAN}

Wilayah PPKAB memiliki luas 300ha dan berada pada koordinat 6031'788” LS dan 106049'727"BT (Arrijani, 2008). Ketinggian berkisar antara 700-1.500 m dpl dan memiliki topografi berupa perbukitan yang berjajar memanjang dari Timur ke Barat. Di studi area Bodogol, curah hujan rata-rata setiap bulan yaitu berkisar 312,2 mm dengan curah hujan tertinggi pada bulan Desember yaitu $733 \mathrm{~mm}$ dengan suhu minimum rata-rata $18^{\circ} \mathrm{C}$ dan suhu maksimum rata-rata $32^{\circ} \mathrm{C}$ (Ario, et al., 2011).

PPKA memiliki beberapa jalur penelitian yang mencakup hampir seluruh tipe habitat di kawasan tersebut. Tujuan pembuatan jalur-jalur ini adalah sebagai sarana untuk memudahkan kegiatan penelitian, meskipun beberapa jalur lebih difokuskan untuk jalur studi wisata. Adapun jalar-jalur penelitian tersebut antara lain: Cipadaranteun, Afrika, Cikaweni, Rasamala, Tangkil, Cipanyairan I dan Cipanyairan II. Walaupun jalur-jalur tersebut memang difungsikan untuk kegiatan penelitian, namun ada beberapa jalur yang jarang dilalui yaitu Tangkil, Cipanyairan I dan Cipanyairan II. Ketiga jalur ini jarang digunakan untuk penelitian karena jaraknya yang jauh dan kondisi jalur yang terjal, tertutup oleh herba dan perdu sehingga sulit untuk dilalui (Ario, et al., 2011).

\section{METODE}

Penelitian dilaksanakan mulai dari November 2011 sampai dengan Maret 2012. Pencarian jenis-jenis reptilia dilakukan dengan menelusuri semua jalur penelitian, kecuali Tangkil, Cipanyairan I dan Cipanyairan II. Pencarian dilakukan pada siang hari pukul 05.00 -11.00 WIB dan malam hari pukul 19.00 - 24.00 WIB. Teknik yang digunakan dalam pencarian yaitu Survei Penjumpaan Visual (Visual Encounter Survey / VES). Pencarian reptilia dilakukan dengan menelusuri jalur dan mengamati sekelilingnya (tepi jalur). Batas jarak tepi jalur yang digunakan adalah 3 meter dari pusat jalur. Pencarian juga dilakukan dengan melihat di bawah batu, kayu-kayu lapuk, semak dan pohon untuk mengoptimalisasikan perolehan data.

Setiap ditemukan jenis reptilia, selanjutnya diidentifikasi dan dilakukan pencatatan data lokasi ditemukannya jenis tersebut. Jenis yang tidak bisa diidentifikasi secara langsung di lapangan, akan disimpan dalam kantung sampel untuk diidentifikasi di camp atau laboratorium. Hasil dari data jenis reptilia yang diperoleh selanjutnya akan dihitung dengan menggunakan indeks keanekaragaman Shannon-Wiener.

Selain data-data tersebut, kami juga mengambil beberapa data kondisi fisik lingkungan, seperti suhu, kelembaban, dan ketinggian. Data suhu dan kelembaban diperoleh dengan menggunakan Kestrel 3000 Pocket Weather Meter, sedangkan data ketinggian diukur dengan menggunakan altimeter manual. 


\begin{tabular}{|c|c|c|c|c|c|c|c|}
\hline Jenis Reptilia & AFR & CKW & $\mathrm{CPD}$ & RSM & Kanopi & Jumlah & $\mathrm{H}$ \\
\hline \multicolumn{8}{|l|}{ Agamidae } \\
\hline Gonocephalus chamaeleontinus & 1 & & & & & 1 & 0,027 \\
\hline Gonocephalus kuhlii & 6 & 2 & 2 & 1 & & 11 & 0,128 \\
\hline Draco volans & 1 & & & & & 1 & 0,027 \\
\hline Bronchocela jubata & & & 2 & & & 2 & 0,045 \\
\hline \multicolumn{8}{|l|}{ Colubridae } \\
\hline Ahaetulla prasina & & & & 1 & & 1 & 0,027 \\
\hline Aplopertura boa & & & 1 & & & 1 & 0,027 \\
\hline Boiga nigriceps & & & & 1 & & 1 & 0,027 \\
\hline Calamaria linnaei & & & & 2 & & 2 & 0,045 \\
\hline Calamaria schelgeli & & & & 1 & & 1 & 0,027 \\
\hline Dendrelaphis pictus & 3 & & & 1 & & 4 & 0,072 \\
\hline Pareas carinatus & 1 & 2 & & & & 3 & 0,060 \\
\hline Rhabdophis chrysargus & 1 & & 2 & & & 3 & 0,060 \\
\hline Xenodermus javanus & 2 & 1 & & & & 3 & 0,060 \\
\hline Xenopeltis unicolor & 2 & & & & & 2 & 0,045 \\
\hline \multicolumn{8}{|l|}{ Elapidae } \\
\hline Bungarus candidus & & & & & 1 & 1 & 0,027 \\
\hline Calliophis intestinalis & & & & & 1 & 1 & 0,027 \\
\hline \multicolumn{8}{|l|}{ Viperidae } \\
\hline Trimeresurus puniceus & 1 & 3 & & & & 4 & 0,072 \\
\hline \multicolumn{8}{|l|}{ Gekkonidae } \\
\hline Cyrtodactylus marmoratus & 2 & & & 1 & & 3 & 0,060 \\
\hline Hemydactylus frenatus & 5 & & & & & 5 & 0,083 \\
\hline Ptychozoon kuhlii & 2 & 2 & & & & 4 & 0,072 \\
\hline \multicolumn{8}{|l|}{ Scincidae } \\
\hline Dasia olivasea & 1 & & & & & 1 & 0,027 \\
\hline Eutropis rugifera & 1 & & & & & 1 & 0,027 \\
\hline Eutropis multifasciata & 3 & 3 & & 6 & & 12 & 0,133 \\
\hline Jumlah & 32 & 13 & 7 & 14 & 2 & 68 & 1,205 \\
\hline
\end{tabular}

Keterangan : AFR = Afrika, CKW = Cikaweni, $\mathrm{CPD}=$ Cipadaranteun, $\mathrm{RSM}$ = Rasamala, Kanopi = Jalur Kanopi

\section{HASIL}

\section{KOMPOSISI JENIS REPTILIA}

Berdasarkan hasil penelitian dari bulan November 2011 - Maret 2012 dikawasan Pusat Pendidikan Konservasi Alam Bodogol, Taman Nasional Gunung Gede Pangrango diperoleh 66 individu reptilia yang berada dalam satu bangsa, yaitu Squamata. Jumlah jenis yang ditemukan sebanyak 23 jenis dari 6 suku dan 21 marga. Setiap pertemuan dengan jenis reptilia dicatat dan di akumulasikan.

Pada Tabel 1 terlihat bahwa di PPKAB saat ini hanya ditemukan jenis dari bangsa Squamata saja. Sedangkan jika dilihat dari jenis yang ditemukan di masing-masing lokasi penelitian jumlahnya bervariasi dan yang paling banyak adalah di jalur Afrika (15 jenis) kemudian diikuti dengan jalur Rasamala ( 8 jenis), Cikaweni ( 6 jenis), Cipadaranteun (4 jenis) dan Kanopi ( 2 jenis). Dari sejumlah jenis reptilia yang ditemukan paling banyak adalah bangsa ular, yaitu sebanyak 13 jenis dari suku Colubridae (10 jenis), suku Elapidae ( 2 jenis) dan Viperidae ( 1 jenis), kemudian diikuti oleh suku Scincidae sebanyak 4 jenis, Agamidae sebanyak tiga jenis dan Gekkonidae sebanyak tiga jenis. Komposisi reptilia yang ditemukan di PPKAB terangkum dalam grafik pada Gambar 1 dan Gambar 2. 


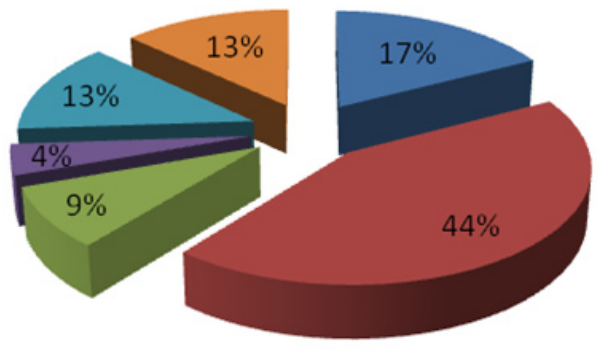

- Agamidae

- Colubridae

Elapidae

Viperidae

- Gekkonidae

a Scincidae

\section{Gambar 1. Komposisi Reptilia berdasarkan Suku}

Pada penelitian ini jenis yang sering ditemukan adalah jenis Eutropis multifasciata (12 individu), kemudian diikuti dengan Gonocephalus kuhlii (11 individu), Hemydactylus frenatus (5 individu), Dendrelaphis pictus (4 individu), Ptychozoon kuhlii (4 individu), Trimeresurus puniceus (4 individu), Cyrtodactylus marmoratus (3 individu), Pareas carinatus ( 3 individu), Rhabdophis crysargus (3 individu), Xenodermus javanus ( 3 individu), Bronchocela jubata (2 individu), Calamaria linnea (2 individu), Xenopeltis unicolor (2 individu) dan satu individu pada jenis Ahaetula prasina, Aplopeltura boa, Boiga nigriceps, Calamaria schelgeli, Dasiao livacea, Draco Volans, Eutropis rugifera, Gonocephalus chameleontinus

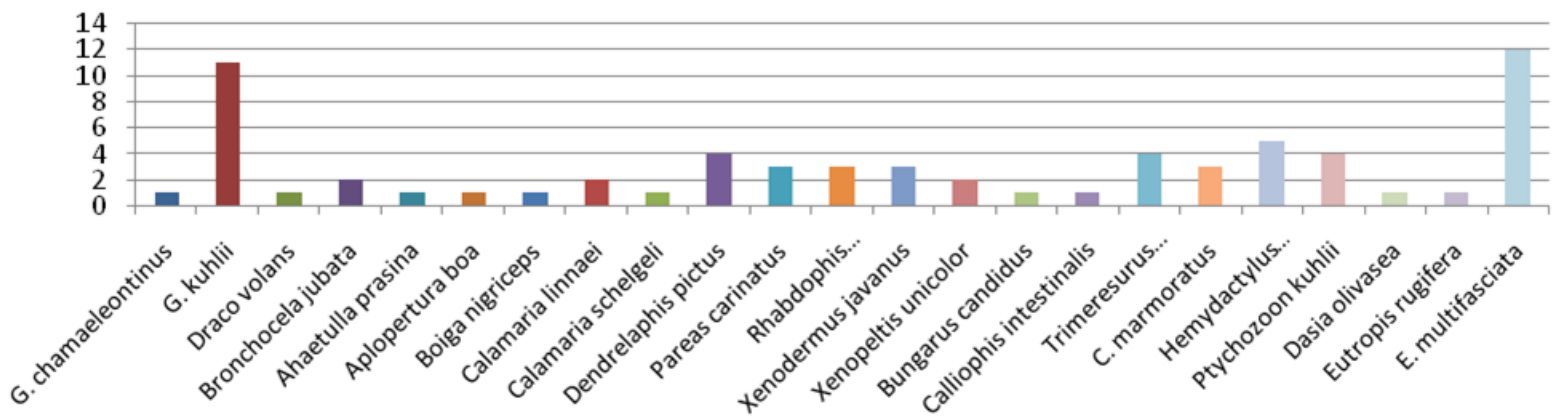

Gambar 2. Diagram komposisi jenis reptilia di Pusat Pendidikan dan Konservasi Alam Bodogol, TNGGP

\section{KONDISI FISIK LINGKUNGAN}

Parameter fisik lingkungan yang diambil meliputi kecepatan angin, kelembaban, suhu udara dan ketinggian. Perbandingan rata-rata parameter fisik pada tiap jalur dapat dilihat pada tabel 2. Parameter fisik lingkungan di atas merupakan rata-rata dari data yang diambil saat pengambilan sampel tiap jalur. Jalur Rasamala memiliki ketinggian paling rendah, yaitu 720-823 mdpl dan jalur Afrika berada pada ketinggian yang paling tinggi, yaitu 824-860 mdpl. Jalur Cipadaranteun memiliki kecepatan angin dan kelembapan paling tinggi dibanding jalur lainnya dan memiliki suhu terendah.

\begin{tabular}{llllll}
\hline \multicolumn{7}{c}{ Tabel 2. Parameter fisik lingkungan } \\
\hline Parameter fisik & AFR & CKW & CPD & RSM & Kanopi \\
\hline Kecepatanangin & 0.27 & 0.18 & 0.42 & 0.06 & - \\
Kelembapan (\%) & 87 & 76 & 90 & 85 & - \\
Suhu $\left({ }^{\circ} \mathrm{C}\right)$ & 23.07 & 22.99 & 22.58 & 24.40 & - \\
Ketinggian (m dpl) & $740-860$ & $820-855$ & $860-870$ & $720-830$ & - \\
\hline Keterangan : AFR = Afrika, CKW = Cikaweni, CPD = Cipadaranteun, RSM = Rasamala, Kanopi = \\
\multicolumn{7}{c}{ Jalur Kanopi } \\
\hline
\end{tabular}




\section{PEMBAHASAN}

Komposisi jenis reptilia didominasi oleh jenis-jenis reptilia dari suku Colubridae. Berdasarkan taksonomi, suku Colubridae merupakan kelompok ular yang kompleks. Kelompok suku ini diklasifikasikan berdasarkan sedikit persamaan karakter atau merupakan kumpulan dari jenis-jenis ular yang tidak termasuk ke dalam suku lain (Cox, et al., 1998; Vitt dan Caldwell, 2009). Sehingga jenis-jenis dari suku ini umumnya memiliki bentuk, sifat ekologi, dan mangsa yang berbeda. Perbedaan 3 faktor tersebut menyebabkan jenis-jenis ular ini dapat berbagi di dalam suatu habitat yang sama dan sangat kecil mengalami perselisihan. Selain itu, suku Colubridae juga memiliki anggota jenis yang paling banyak dibandingkan dengan suku-suku lain di dalam kelompok reptilia (Cox, et al., 1998). Oleh karena itu, suku ini umumnya dapat ditemukan lebih banyak di suatu daerah (dibandingkan dengan suku lain), selama kondisi fisik di suatu daerah itu sesuai sebagai tempat hidupnya.

Dari data penelitian, diketahui bahwa suku Viperidae merupakan suku yang paling sedikit jenisnya (hanya satu jenis), yaitu Trimeresurus puniceus. Di Jawa, jumlah jenis ular dari suku Viperidae memang sangat sedikit dan masingmasing memiliki persebaran geografis yang spesifik. Hingga saat ini, Bodogol diketahui hanya memiliki satu jenis dari suku Viperidae. Dua kerabat Trimeresurus puniceus, yaitu: Cryptolitrops albolabris dan Daboia ruselli, meskipun secara biogeografis memungkinkan untuk ditemukan di Bodogol (de Rooij, 1917; David dan Vogel, 1996). Namun hingga sekarang belum ada laporan yang menyatakan keberadaan dua jenis ular itu di Bodogol.

Gonocephalus kuhlii merupakan jenis dengan persebarannya paling tinggi, jenis ini ditemukan hampir di semua jalur. Sedangkan jenis yang paling paling dominan adalah Eutropis multifasciata. Eutrophis multifasciata merupakan jenis kadal yang sangat adaptif di berbagai tipe habitat, bahkan dapat hidup di daerah yang sangat terganggu (Brown dan Alcala, 1980). Kadal ini merupakan kadal kosmopolitan, jenis tidak terlalu memilih jenis mangsa untuk pakannya (opportunis) dan juga dapat bersarang di berbagai kondisi habitat (Kurniati, et al., 2000).

Berdasarkan data yang diperoleh, Bodogol memiliki keanekaragaman reptilia yang sedang $\mathrm{H}=1,205$ ). Meskipun demikian, bila dibandingkan dengan kekayaan jenis reptilia yang dilaporkan oleh Mumpuni (2001) dan Kurniati (2004) jumlah jenis reptilia yang terdapat di Bodogol mencapai $72 \%$ dari total jenis reptilia yang diperoleh dari empat kawasan di Taman Nasional Gunung Halimun. Sebanyak 14 jenis dari total 32 jenis reptilia yang diperoleh

di Taman Nasional Gunung Halimun dapat pula ditemukan di Bodogol. Hal ini membuktikan bahwa meskipun Bodogol memiliki area yang tidak cukup luas, namun wilayah tersebut memiliki beberapa habitat yang sesuai sebagai tempat hidup berbagai jenis reptilia.

\section{KESIMPULAN}

Keanekaragaman jenis reptilia di Pusat Pendidikan Konservasi Alam Bodogol dikategorikan sedang dengan nilai Indeks Keanekaragaman (H') Shannon-Wiener sebesar 1,205. Namun kekayaan jenis reptilia di Bodogol mencapai 70\% dari kekayaan jenis reptilia di Taman Nasional Gunung Halimun.

\section{DAFTAR PUSTAKA}

Apririasari, L. 2002. Inventarisasi Jenis Ular di Pusat Pendidikan Konservasi Alam Bodogol Taman Nasional Gunung Gede-Pangrango Jawa Barat. Skripsi. Universitas Kristen Duta Wacaca.

Ario, A. 2011.Panduan Lapangan Mengenal Satwa Taman Nasional Gunung Gede Pangrango. Conservation 
International Indonesia: Jakarta.

Brown, W. C. dan A. C. Alcala. 1980. Philippine Lizards of Family Scincidae. Silliman University Nat. Sci. Monogr. Ser 2, Dumaguete City. Vii + 264 pp.

Cox, M.J., van Dijk, P.P., Nabhitabhata, J., Thirakhupt, K. (1998): A Photographic Guide to Snakes and other Reptiles of Peninsular Malaysia, Singapore and Thailand. New Holland Publishers (UK) Ltd. Singapore.

David P, Vogel G. 1996. The Snakes of Sumatra. An Annotated Checklist and Key with Natural History. Notes. 1-261. - Edition Chimaira, Frankfurt am Main.

de Rooij, N. DE 1917. The Reptiles of the Indo-Australian Archipelago. Il. Ophidia. Leiden (E. J. Brill), xiv + 334 S.

Kurniati, H. 2004. The reptiles species in Gunung Halimun National Park, West Java, Indonesia. Biological News. Vol. 7 (1) special edition: 73-79.

Kurniati, H., A.H. Tjakrawidjaja \& I. Maryanto. 2000. Ecological feeding analysis of Mabuya multifasciata from Indonesian Botanical Garden in Bali (Lacertilia: scincidae). Biota 5 (3) : 107-114.

Mumpuni.2001. Keanekaragaman Herpetofauna di Taman Nasional Gunung Halimun, Jawa Barat. Edisi Khusus Biodiversitas Taman Nasional Gunung Halimun. Bidang Zoologi, Puslit Biologi-LIPI Bogor. Volume 5, Nomor 6.

Riyanto, Awal.2008. Komunitas Herpetofauna di Taman Nasional Gunung Ciremai, Jawa Barat. Jurnal Biologi Indonesia 4(5): 349-358 (2008)). Museum Zoolocum Bogoriense.

Vitt, L. J., \& Caldwell, J. P. (2009). Herpetology: An Intoroductory Biology of Amphibians and Reptiles (Third Edition ed.). London: Elsevier Inc. 